\title{
OPEN Isolation of Borrelia miyamotoi and other Borreliae using a modified BSK medium
}

\author{
Adam J. Replogle ${ }^{1}$, Christopher Sexton ${ }^{1}$, John Young ${ }^{1}$, Luke C. Kingry ${ }^{1}$, Martin E. Schriefer ${ }^{1}$, \\ Marc Dolan ${ }^{1}$, Tammi L. Johnson ${ }^{1,4}$, Neeta P. Connally ${ }^{2}$, Kerry A. Padgett ${ }^{3} \&$ \\ Jeannine M. Petersen ${ }^{1 \bowtie}$
}

Borrelia spirochetes are the causative agents of Lyme borreliosis (LB) and relapsing fever (RF). Despite the steady rise in infections and the identification of new species causing human illness over the last decade, isolation of borreliae in culture has become increasingly rare. A modified Barbour-StoennerKelly (BSK) media formulation, BSK-R, was developed for isolation of the emerging RF pathogen, Borrelia miyamotoi. BSK-R is a diluted BSK-II derivative supplemented with Lebovitz's L-15, mouse and fetal calf serum. Decreasing the concentration of CMRL 1066 and other components was essential for growth of North American B. miyamotoi. Sixteen B. miyamotoi isolates, originating from Ixodes scapularis ticks, rodent and human blood collected in the eastern and upper midwestern United States, were isolated and propagated to densities $>10^{8}$ spirochetes $/ \mathrm{mL}$. Growth of five other RF and ten different LB borreliae readily occurred in BSK-R. Additionally, primary culture recovery of 20 isolates of Borrelia hermsii, Borrelia turicatae, Borrelia burgdorferi and Borrelia mayonii was achieved in BSK-R using whole blood from infected patients. These data indicate this broadly encompassing borreliae media can aid in in vitro culture recovery of RF and LB spirochetes, including the direct isolation of new and emerging human pathogens.

Primary culture recovery is often considered the benchmark for proof of infection, but for many bacterial infections, including Borrelia spp., this proof is rarely achieved. Reasons for diminished use of culture for borreliae include their fastidious nature and strict requirement for exogenous nutrients and cofactors, lengthy in vitro doubling times, and the complex and expensive nature of culture media and its monitoring requirements ${ }^{1,2}$. Further, as infection can often be demonstrated by other indirect (e.g. serology) and direct (e.g. PCR) methods in a matter of hours, culture attempts may appear unnecessary and burdensome. Nevertheless, given the significant and growing public health importance of tickborne diseases ${ }^{3,4}$, including those caused by Borrelia species, the value of culture cannot be underestimated, especially as it pertains to conclusive demonstration of human infection in new or unexpected geographic regions and isolation of novel pathogens.

Human illness causing borreliae are divided into two genetically distinct groups, the Borrelia burgdorferi sensu lato (Bbsl) complex and the relapsing fever (RF) group ${ }^{2}$. Lyme borreliosis (LB), the most common tickborne illness in the northern hemisphere, results from infection by spirochetes in the Bbsl genospecies complex, which are transmitted through the bite of hard ticks (Ixodidae). Tickborne and louseborne RF develops upon infection by spirochetes in the RF group. Tickborne RF borreliae are transmitted by soft ticks (Argasidae); however, this paradigm shifted upon discovery of Borrelia miyamotoi $i^{5}$. Phylogenetic analysis places it within the RF borreliae, yet, B. miyamotoi is transmitted by Ixodes ticks ${ }^{5}$.

Historical attempts to propagate RF borreliae ${ }^{6}$ led to fundamental descriptions of their morphology, but it was not until 1971 that an in vitro culture media enabling primary recovery and continuous passage of the RF spirochete, Borrelia hermsii, was established ${ }^{7}$. Shortly thereafter (1983) the recovery and maintenance of a newly identified human pathogen, Borrelia burgdorferi, an agent of $\mathrm{LB}^{8}$, was described using a fortified version (Barbour-Stoenner-Kelly; BSK) of Stoenner-Kelly's medium. In 1986, researchers from the Max von Pettenkofer Institute altered BSK media to culture B. burgdorferi in what has been referred to as modified Kelly-Pettenkofer

\footnotetext{
${ }^{1}$ Division of Vector-Borne Diseases, Centers for Disease Control and Prevention, Fort Collins, CO 80521, USA. ${ }^{2}$ Department of Biological and Environmental Sciences, Western Connecticut State University, Danbury, CT 06810, USA. ${ }^{3}$ California Department of Public Health, Infectious Diseases Branch/Vector-Borne Disease

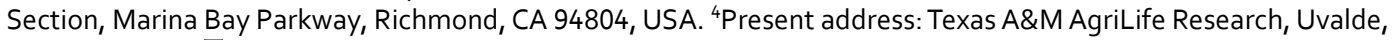
TX 78801, USA. ${ }^{\square}$ email: nzp0@cdc.gov
} 


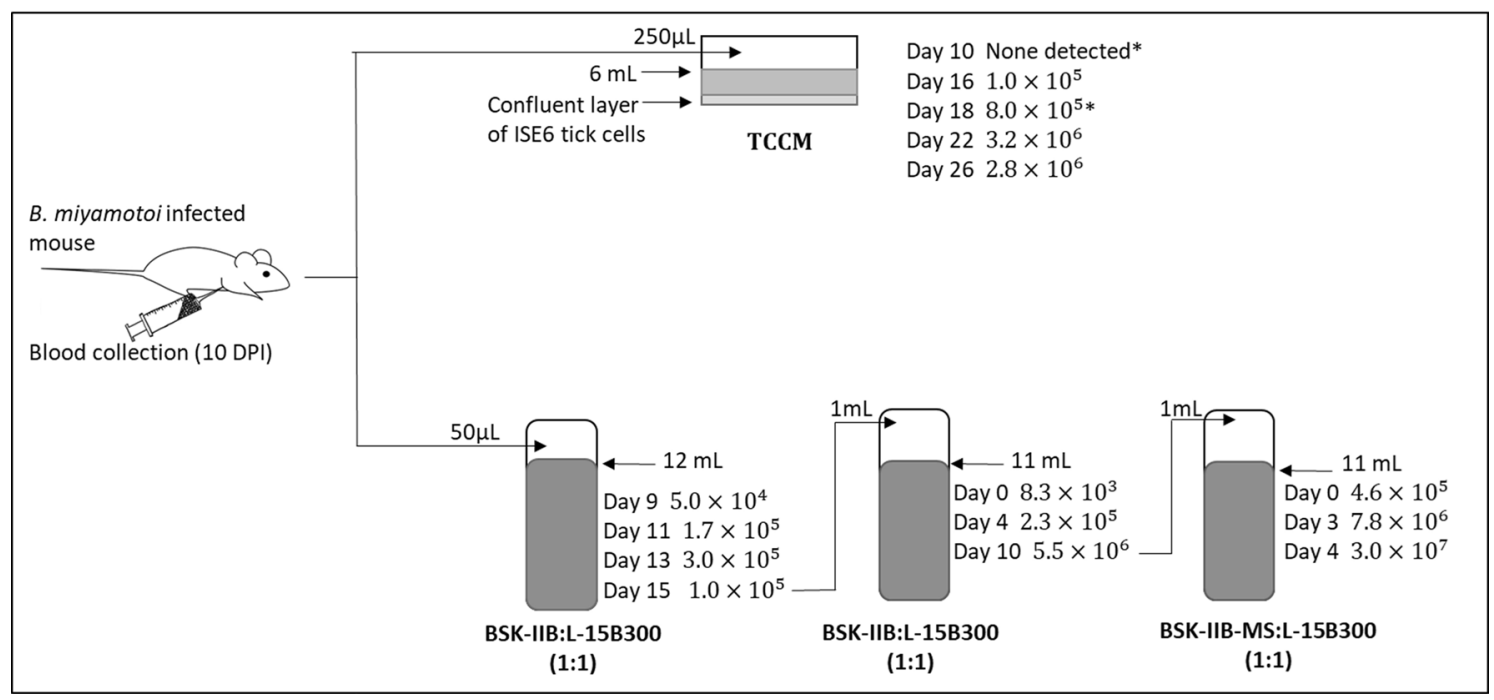

Figure 1. In vitro culture of North American B. miyamotoi. I. scapularis egg homogenate (glpQ PCR positive, ospA PCR negative) was inoculated subcutaneously into a BALB/c mouse. Borrelia miyamotoi DNA was detected in mouse blood on days six and ten post-infection; at the later time point, spirochetes were also visualized by dark field microscopy and confirmed as $B$. miyamoto $i$ by $16 \mathrm{~S} \mathrm{rDNA}$ sequencing. On day ten, $B$. miyamotoi infected mouse blood was collected and used to seed liquid cultures, with (top) and without (bottom) ISE6 tick cells. Media compositions are shown. Borrelia miyamotoi concentrations are presented by day postseeding of cultures. Concentrations shown are spirochetes $/ \mathrm{mL}$, as determined via counting of motile spirochetes by dark field microscopy. The * indicates timepoint at which TCCM was removed from tick cell co-cultures, centrifuged, and the resulting pellet resuspended in fresh TCCM and re-incubated with ISE6 cells. Day of passage into new media is shown by arrows (bottom); volumes used for passage are displayed.

(MKP) medium ${ }^{9}$. Today, primary culture recovery of borreliae, in both the RF and LB groups, is a more limited and specialized practice, perhaps even, a neglected laboratory tool. A standardized formulation, termed BSK- $\mathrm{H}^{10}$, is the only commercial formulation available.

Over the last decade several new Borrelia pathogens have emerged as causative agents of human illness. These include Borrelia mayonii, a genospecies within B. burgdorferi sensu lato, which was first described in 2016 as a novel cause of LB in the upper midwestern U.S. ${ }^{11}$. Infected patients demonstrate unusually high spirochetemia as compared to other B. burgdorferi sensu lato genospecies. Borrelia miyamotoi, first described in Ixodes ticks in Japan in 1995, was identified as a human pathogen in 2011 in Russia and 2015 in the United States ${ }^{5,12,13}$. Isolation of this spirochete from U.S. sources has proved challenging. Attempts to cultivate B. miyamotoi directly from $I$. scapularis and human CSF using BSK-H, were unsuccessful ${ }^{13,14}$.

A medium enabling direct isolation of species encompassing both the RF and LB borreliae groups may help to improve borreliae culture, while simultaneously facilitating isolation of new species. Here we describe the development of a modified BSK-II media formulation, BSK-R, which enabled the primary culture recovery of multiple U.S. B. miyamotoi isolates as well as other RF and LB borreliae, including B. mayonii.

\section{Results}

In vitro isolation of B. miyamotoi RI13-2395. In vitro isolation initially focused on B. miyamotoi from U.S. sources, given the prior lack of isolation in BSK-H. No growth occurred when blood from a laboratory infected mouse was seeded into BSK-IIB. In contrast, growth of B. miyamotoi occurred when the same blood was seeded into a confluent monolayer of ISE6 tick cells in tick cell co-culture medium (TCCM) as well as into BSK-IIB and L-15B300, the primary component of TCCM, combined at a ratio of 1:1 (Fig. 1). In the latter case, subsequent passage into BSK-IIB:L-15B300 (1:1), with BALB/c mouse serum substituted for rabbit serum (BSKIIB-MS), yielded a peak spirochete density of $3.0 \times 10^{7}$ spirochetes $/ \mathrm{mL}$. The recovered spirochetes were confirmed as B. miyamotoi by glpQ PCR and $16 \mathrm{~S}$ rDNA sequencing (426 nucleotides, $100 \%$ identity to $B$. miyamoto $i$ LB-2001). At this time, a strain name, RI13-2395, was assigned and either this actively growing culture or frozen stocks (passage 2; P2) used for subsequent experiments.

Inhibition of B. miyamotoi growth in BSK-IIB. To determine if growth of B. miyamotoi RI13-2395 in BSK-IIB-MS:L-15B300 (1:1) was due to the addition of L-15B300 or from decreased concentrations of BSK-IIB ingredients, side-by-side growth comparisons were performed with BSK-IIB-MS:L-15B300 (1:1), BSK-IIB-MS alone, and BSK-IIB-MS mixed with $\mathrm{H}_{2} \mathrm{O}$ at four different ratios (Fig. 2a). Actively growing spirochetes (P2) were inoculated into all media formulations at a final concentration of $1.6 \times 10^{5}$ spirochetes $/ \mathrm{mL}$. Notably, no growth of B. miyamotoi occurred in BSK-IIB-MS. Only when BSK-IIB-MS was diluted with $\mathrm{H}_{2} 0$ did growth of B. miyamotoi ensue. Similar growth $\left(8 \times 10^{6}\right.$ spirochetes $/ \mathrm{mL}$; doubling time of $\left.17 \mathrm{~h}\right)$ was achieved on day four for the 1:1,3:2 and 2:1 mixtures as compared to BSK-IIB-MS:L-15B300 (1:1) $\left(10^{7}\right.$ spirochetes $/ \mathrm{mL}$; doubling time of $\left.16 \mathrm{~h}\right)$. The highest peak densities were observed when BSK-IIB-MS was diluted with $\mathrm{H}_{2} 0$ at ratios of 1:1 and 3:2. 

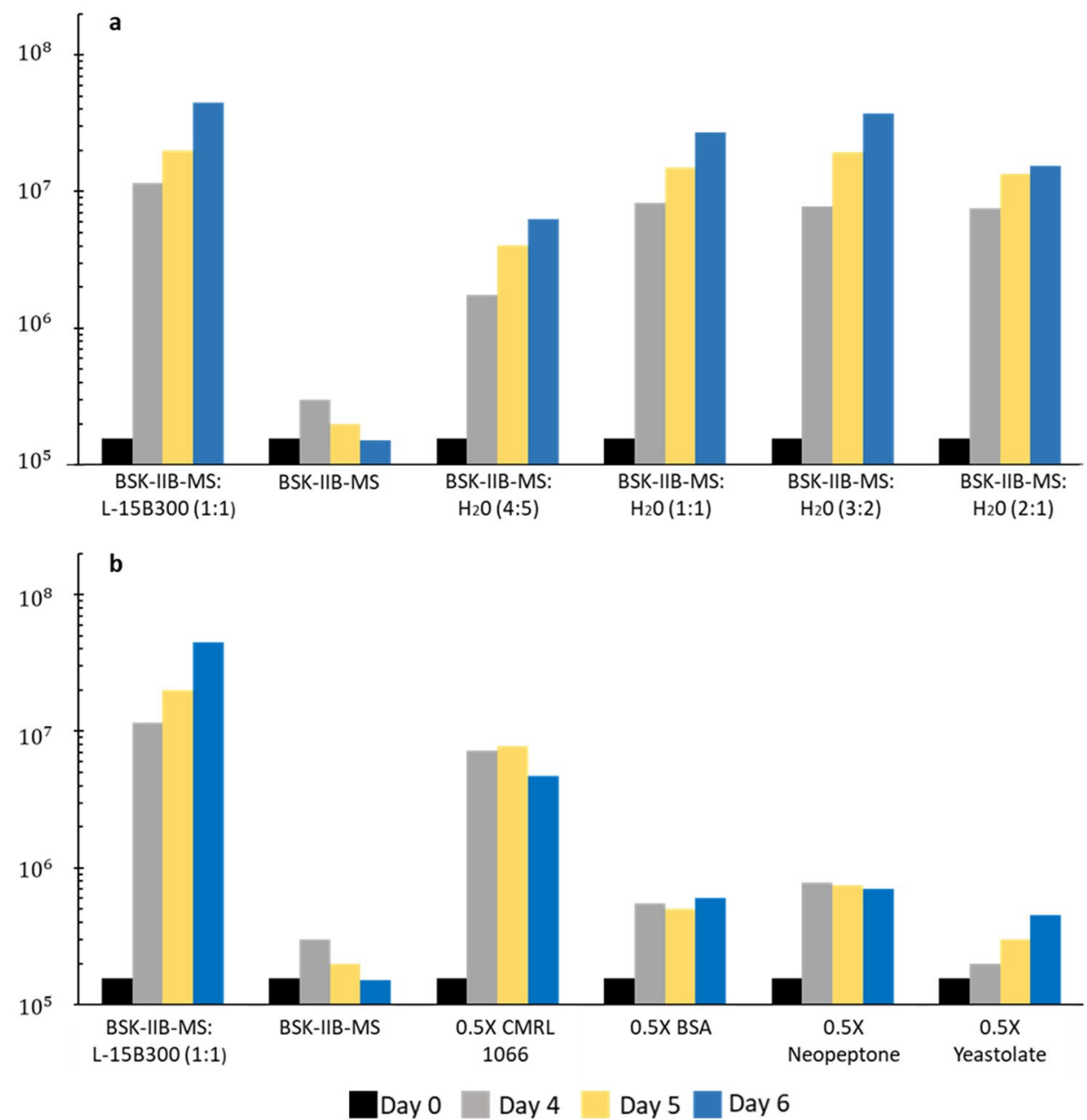

Figure 2. Inhibition of B. miyamotoi growth in BSK-IIB-MS. (a) Side-by-side comparisons of observed cell densities (spirochetes/mL) upon inoculation of BSK-IIB-MS:L-15B300 (1:1), BSK-IIB-MS alone and BSK-IIB-MS diluted with $\mathrm{H}_{2} \mathrm{O}$ at the indicated ratios. Actively growing spirochetes were seeded into media formulations at a final concentration of $1.6 \times 10^{5}$ spirochetes $/ \mathrm{mL}$. The percentages of BSK-IIB-MS to $\mathrm{H}_{2} 0$ in the 1:1 and 3:2 ratios, was 50:50 and 60:40, respectively. (b) Side by side comparisons of cell densities in BSK-IIB:L15B300 (1:1), BSK-IIB-MS alone, and BSK-IIB-MS with individual indicated components reduced by half. The final concentration of indicated components was $4.04 \mathrm{~g} / \mathrm{L}$ CMRL 1066 10X w/o L-glutamine, $20.85 \mathrm{~g} / \mathrm{L}$ BSA, $2.01 \mathrm{~g} / \mathrm{L}$ Bacto neopeptone and $0.84 \mathrm{~g} / \mathrm{L}$ Bacto TC yeastolate. Actively growing spirochetes were seeded into media formulations at a final concentration of $1.6 \times 10^{5}$ spirochetes $/ \mathrm{mL}$. (a,b) Spirochete densities by day are indicated by color: day 0 , black; day 4 , grey; day 5 , yellow; day 6 , blue.

To narrow down which component/s of BSK-IIB-MS might be inhibitory, the final concentration of each of the ingredients, with the exception of serum and dithiothreitol (DTT), was singly reduced by half in BSK-IIB-MS. Decreasing the concentration of CMRL 1066 w/o L-glutamine by 50\% (final concentration of $4.04 \mathrm{~g} / \mathrm{L}$ ) yielded a greater than 20 -fold increase in spirochete density at day four post inoculation (doubling time of $17 \mathrm{~h}$ ) (Fig. 2b). Individually reducing the concentration of proteinaceous components of BSK-IIB, Bacto neopeptone, bovine serum albumin (BSA), and Bacto TC yeastolate, and other components, by half did not relieve inhibition of $B$. miyamotoi growth to the same degree as was evidenced for CMRL 1066 (Fig. 2b; data not shown). Continuous growth of spirochetes was not observed beyond day four when any single component was reduced by half.

BSK-R. BSK-IIB-MS diluted 40\% with water [BSK-IIB-MS: $\mathrm{H}_{2} \mathrm{O}$ (3:2)] served as the basis for further media optimization using frozen P2 stocks of B. miyamotoi RI13-2395. Lebovitz's L-15, a primary component of $\mathrm{L}-15 \mathrm{~B} 300$, was added at final concentrations ranging from 4 to $10 \mathrm{~g} / \mathrm{L}$ to look for growth augmentation. A final concentration of either 5 or $6.7 \mathrm{~g} / \mathrm{L}$ [final concentration in BSK-IIB-MS:L-15B300 (1:1)] stimulated growth of $B$. miyamotoi by three-fold as compared to BSK-IIB-MS diluted $40 \%$ with water. A spirochete density of $3.0 \times 10^{7}$ cells $/ \mathrm{mL}$ was achieved after six days of growth when $5 \mathrm{~g} / \mathrm{L}$ Lebovitz's L-15 was included. At the uppermost concentration tested, $10 \mathrm{~g} / \mathrm{L}$, spirochete growth was impaired. 


\begin{tabular}{|l|l|l|l|}
\hline BSK media components & BSK-IIB & BSK-IIB-MS & BSK-R \\
\hline Probumin bovine serum albumin univeral grade, powder (Millipore Sigma, St. Louis, MA) & $41.7 \mathrm{~g} / \mathrm{L}$ & $41.7 \mathrm{~g} / \mathrm{L}$ & $25 \mathrm{~g} / \mathrm{L}$ \\
\hline CMRL 1066 10X w/o L-glutamine (powder) (US Biological, Salem, MA) & $8.08 \mathrm{~g} / \mathrm{L}$ & $8.08 \mathrm{~g} / \mathrm{L}$ & $4.3 \mathrm{~g} / \mathrm{L}$ \\
\hline Gibco Bacto neopeptone (Fisher Scientific, Pittsburgh, PA) & $4.17 \mathrm{~g} / \mathrm{L}$ & $4.17 \mathrm{~g} / \mathrm{L}$ & $2.5 \mathrm{~g} / \mathrm{L}$ \\
\hline HEPES sodium salt, 99+\%, ACROS Organics (Fisher Scientific) & $5.0 \mathrm{~g} / \mathrm{L}$ & $5.0 \mathrm{~g} / \mathrm{L}$ & $2.2 \mathrm{~g} / \mathrm{L}$ \\
\hline Sodium citrate dihydrate (Millipore Sigma) & $0.583 \mathrm{~g} / \mathrm{L}$ & $0.583 \mathrm{~g} / \mathrm{L}$ & $0.35 \mathrm{~g} / \mathrm{L}$ \\
\hline D-(+)-Glucose (Millipore Sigma) & $5.83 \mathrm{~g} / \mathrm{L}$ & $5.83 \mathrm{~g} / \mathrm{L}$ & $5.0 \mathrm{~g} / \mathrm{L}$ \\
\hline Sodium pyruvate (Millipore Sigma) & $0.667 \mathrm{~g} / \mathrm{L}$ & $0.667 \mathrm{~g} / \mathrm{L}$ & $0.4 \mathrm{~g} / \mathrm{L}$ \\
\hline N-Acetyl-D-glucosamine, cell culture reagent (MP Biomedicals, Irvine, CA) & $0.333 \mathrm{~g} / \mathrm{L}$ & $0.333 \mathrm{~g} / \mathrm{L}$ & $0.2 \mathrm{~g} / \mathrm{L}$ \\
\hline Sodium bicarbonate (Millipore Sigma) & $1.83 \mathrm{~g} / \mathrm{L}$ & $1.83 \mathrm{~g} / \mathrm{L}$ & $0.98 \mathrm{~g} / \mathrm{L}$ \\
\hline Gibco Bacto TC yeastolate (Fisher Scientific) & $1.67 \mathrm{~g} / \mathrm{L}$ & $1.67 \mathrm{~g} / \mathrm{L}$ & $1.0 \mathrm{~g} / \mathrm{L}$ \\
\hline L-cysteine hydrochloride monohydrate (Fisher Scientific) & $0.233 \mathrm{~g} / \mathrm{L}$ & $0.233 \mathrm{~g} / \mathrm{L}$ & $0.14 \mathrm{~g} / \mathrm{L}$ \\
\hline Mouse BALB/c serum (Innovative Research, Novi, MI) & None & $12 \%$ & $7 \%$ \\
\hline Rabbit serum, sterile, trace-hemolyzed (Pel-Freez, Rogers, AR) & $12 \%$ & None & $4 \%$ \\
\hline Corning premium fetal bovine serum (Fisher Scientific) & None & None & $2 \%$ \\
\hline Invitrogen UltraPure dithiothreitol (Fisher Scientific) & $0.067 \mathrm{~g} / \mathrm{L}$ & $0.067 \mathrm{~g} / \mathrm{L}$ & $0.04 \mathrm{~g} / \mathrm{L}$ \\
\hline Gibco Leibovitzs L-15 medium, powder (Fisher Scientific) & None & None & $5.0 \mathrm{~g} / \mathrm{L}$ \\
\hline
\end{tabular}

Table 1. BSK media formulations.

Table 1 provides a recipe for the final media formulation, designated BSK-R, which includes $5 \mathrm{~g} / \mathrm{L}$ Leibovitz's L-15 and components of BSK-IIB adjusted to $60 \%$, with the exception of $4.3 \mathrm{~g} / \mathrm{L}$ CMRL-1066 w/o L-glutamine, $5.0 \mathrm{~g} / \mathrm{L}$ glucose as well as $2.2 \mathrm{~g} / \mathrm{L}$ HEPES and $0.98 \mathrm{~g} / \mathrm{L}$ sodium bicarbonate, which were adjusted to give a final $\mathrm{pH}$ of 7.5. Serum was added to a final concentration of $13 \%$ ( $7 \%$ mouse serum, $4 \%$ rabbit serum and $2 \%$ fetal bovine serum).

Comparison of B. miyamotoi growth in BSK-R, BSK-IIB-MS diluted 40\% with water, and BSK-IIB-MS:L$15 \mathrm{~B} 300$ (1:1), using a P2 frozen stock as the starting inoculum, indicated that B. miyamotoi strain RI13-2395 displayed an improved doubling time of $18 \mathrm{~h}$ in BSK-R as compared to $23 \mathrm{~h}$ in the original BSK-IIB-MS:L-15B300 $(1: 1)$ formulation used initially to propagate this strain. The spirochete density achieved at this time point $(96 \mathrm{~h})$ was also two-fold higher in BSK-R as compared to BSK-IIB-MS:L-15B300 (1:1). After eight days, a maximum density was reached, with $1.3 \times 10^{8}, 3.9 \times 10^{7}$ and $7.2 \times 10^{7}$ spirochetes/mL observed in BSK-R, BSK-IIB-MS diluted 40\% with water and BSK-IIB-MS: L-15B300 (1:1), respectively.

Direct isolation of B. miyamotoifrom Ixodes scapularis ticks and Tamias striatus in BSK-R. Seventeen single nymphs, derived from five female adult B. miyamotoi infected I. scapularis ticks, were seeded into BSK-R with antibiotics. Borrelia miyamotoi spirochetes were successfully recovered in 14 of the 17 inoculated cultures, yielding a recovery rate of $82 \%$. The average density without passage was $1.1 \times 10^{7}$ spirochetes $/ \mathrm{mL}$ and the average time to this density was 11.5 days (range seven to 14 days). Spirochetes were confirmed as B. miyamotoi by glpQ PCR and/or 16S rDNA sequencing. Additionally, one isolate, CT13-2396, was genome sequenced, with this sequence made publicly available (GenBank accession numbers CP017126 to CP017140) ${ }^{15}$. When blood (collected with EDTA) from a field collected chipmunk (T. striatus) was inoculated into BSK-R with antibiotics, growth also occurred, albeit at slower rates as compared to I. scapularis ticks. Motile spirochetes $\left(1 \times 10^{4}\right.$ spirochetes $\left./ \mathrm{mL}\right)$ were observed after 13 days. Upon passage of spirochetes to fresh BSK-R, a density of $7.7 \times 10^{6}$ spirochetes was achieved 11 days later. The recovered spirochete was $o s p A$ PCR negative and $g l p Q$ PCR positive.

No growth of B. miyamotoi occurred in BSK-R when nine single minced I. pacificus nymphs, derived from a field collected female adult tick ( $g l p Q$ PCR positive, ospA PCR negative), were incubated for 30 days, including two blind passages into fresh media. Seeding of blood $(20 \mu \mathrm{L})$ from a SCID mouse infected with $B$. miyamotoi via $I$. pacificus feeding, also yielded no growth in BSK-R, however, motile spirochetes $\left(3.5 \times 10^{4}\right.$ spirochetes $\left./ \mathrm{mL}\right)$ were detected microscopically in ISE6 co-cultures and subsequently passaged into BSK-R. The recovered $B$. miyamotoi isolate, CA17-2241, was genome sequenced with the chromosome and large linear plasmid sequences publicly available (GenBank accession numbers CP021872 and CP021873) ${ }^{16}$.

BSK-R supports growth of both relapsing fever and Lyme borreliae. Side-by-side comparisons demonstrated three other RF borreliae, B. hermsii, Borrelia turicatae, and Borrelia recurrentis, grew to high densities without passage in BSK-R and BSK-IIB, with $\sim 10^{8}$ spirochetes $/ \mathrm{mL}$ achieved for all (Table 2). Two B. burgdorferi sensu lato genospecies, B. burgdorferi and B. mayonii, were similarly propagated in both BSK-R and BSK-IIB (Table 2). As expected, the B. miyamotoi isolates recovered in this study, LB-2001 and three B. miyamotoi strains originating from Japan all grew in BSK-R with maximum concentrations ranging from $3.6 \times 10^{7}$ to $1.5 \times 10^{8}$ spirochetes $/ \mathrm{mL}$ after $6-10$ days. In contrast, BSK-IIB was unable to support growth of any North American B. miyamotoi strain, with the exception of B. miyamotoi CA17-2241, which reached a maximum cell density of $4.2 \times 10^{6}$ spirochetes $/ \mathrm{mL}$ after 19 days. For the three B. miyamotoi strains originating from Japan, spirochete motility and growth rate were improved in BSK-R as compared to BSK-IIB. Twelve additional strains encompassing Borrelia 


\begin{tabular}{|c|c|c|c|c|c|c|}
\hline Borrelia group & Borrelia species & $\begin{array}{l}\text { Geographic } \\
\text { origin }\end{array}$ & BSK-IIB growth & $\begin{array}{l}\text { BSK-IIB } \\
\text { maximum density }\end{array}$ & BSK-R growth & $\begin{array}{l}\text { BSK-R maximum } \\
\text { density }\end{array}$ \\
\hline \multirow{15}{*}{ Relapsing fever } & $\begin{array}{l}\text { B. miyamotoi } \\
\text { RI13-2395 }\end{array}$ & United States (RI) & No & NA & Yes & $1.5 \times 10^{8}$ \\
\hline & $\begin{array}{l}\text { B. miyamotoi } \\
\text { CT13-2396 }\end{array}$ & United States (CT) & No & NA & Yes & $1.4 \times 10^{8}$ \\
\hline & $\begin{array}{l}\text { B. miyamotoi } \\
\text { CT15-0838 }\end{array}$ & United States (CT) & No & $\mathrm{NA}$ & Yes & $1.2 \times 10^{8}$ \\
\hline & $\begin{array}{l}\text { B. miyamotoi } \\
\text { CT15-0839 }\end{array}$ & United States (CT) & No & $\mathrm{NA}$ & Yes & $1.2 \times 10^{8}$ \\
\hline & $\begin{array}{l}\text { B. miyamotoi } \\
\text { CT15-0840 }\end{array}$ & United States (CT) & No & NA & Yes & $1.3 \times 10^{8}$ \\
\hline & $\begin{array}{l}\text { B. miyamotoi } \\
\text { CT15-0841 }\end{array}$ & United States (CT) & No & NA & Yes & $1.5 \times 10^{8}$ \\
\hline & $\begin{array}{l}\text { B. miyamotoi } \\
\text { MN16-2304 }\end{array}$ & $\begin{array}{l}\text { United States } \\
(\mathrm{MN})\end{array}$ & No & NA & Yes & $6.8 \times 10^{7}$ \\
\hline & $\begin{array}{l}\text { B. miyamotoi } \\
\text { CA17-2241 }\end{array}$ & United States (CA) & Yes & $4.2 \times 10^{6}$ & Yes & $6.2 \times 10^{7}$ \\
\hline & $\begin{array}{l}\text { B. miyamotoi } \\
\text { LB2001 }\end{array}$ & United States $(\mathrm{CT})$ & No & NA & Yes & $3.6 \times 10^{7}$ \\
\hline & $\begin{array}{l}\text { B. miyamotoi } \\
\text { HT31 }\end{array}$ & Japan & Yes & $9.0 \times 10^{7}$ & Yes & $7.0 \times 10^{7}$ \\
\hline & $\begin{array}{l}\text { B. miyamotoi } \\
\text { HT24 }\end{array}$ & Japan & Yes & $9.0 \times 10^{7}$ & Yes & $1.5 \times 10^{8}$ \\
\hline & $\begin{array}{l}\text { B. miyamotoi } \\
\text { FR64b }\end{array}$ & Japan & Yes & $8.5 \times 10^{7}$ & Yes & $1.3 \times 10^{8}$ \\
\hline & $\begin{array}{l}\text { B. hermsii NE95- } \\
0544\end{array}$ & United States $(\mathrm{CO})$ & Yes & $1.8 \times 10^{8}$ & Yes & $8.5 \times 10^{7}$ \\
\hline & $\begin{array}{l}\text { B. turicatae TX15- } \\
4645\end{array}$ & United States (TX) & Yes & $2.0 \times 10^{8}$ & Yes & $2.0 \times 10^{8}$ \\
\hline & $\begin{array}{l}\text { B. recurrentis } \\
\text { SU99-0699 }\end{array}$ & Republic of Sudan & Yes & $1.5 \times 10^{8}$ & Yes & $1.0 \times 10^{8}$ \\
\hline \multirow{3}{*}{ Lyme } & B. burgdorferi $\mathrm{B} 31$ & United States (NY) & Yes & $2.9 \times 10^{8}$ & Yes & $1.5 \times 10^{8}$ \\
\hline & $\begin{array}{l}\text { B. mayonii MN14- } \\
1420\end{array}$ & $\begin{array}{l}\text { United States } \\
(\mathrm{MN})\end{array}$ & Yes & $2.3 \times 10^{7}$ & Yes & $1.7 \times 10^{8}$ \\
\hline & $\begin{array}{l}\text { B. mayonii MN14- } \\
1539\end{array}$ & $\begin{array}{l}\text { United States } \\
(\mathrm{MN})\end{array}$ & Yes & $1.5 \times 10^{7}$ & Yes & $1.7 \times 10^{8}$ \\
\hline
\end{tabular}

Table 2. Growth comparison of Lyme and relapsing fever Borrelia species in BSK-R and BSK-IIB.

parkeri, Borrelia coriaceae, Borrelia afzelii, Borrelia garinii, Borrelia bissettii, Borrelia lanei, Borrelia valasiana, Borrelia yangtzensis, Borrelia sinica and Borrelia spielmanii all readily proliferated in BSK-R, without passage, to peak motile spirochete densities of $10^{7}$ to $10^{8}$ spirochetes $/ \mathrm{mL}$ (data not shown).

Direct isolation of Borrelia species from human blood and field collected ticks using BSK-R. When 21 human whole bloods (50-500 $\mu \mathrm{L}$ collected with EDTA) from infected patients were inoculated into BSK-R with antibiotics, isolates of both RF (B. miyamotoi, B. hermsii, B. turicatae) and Lyme borreliae (B. mayonii and B. burgdorferi) were successfully recovered (Table 3). For all five species, spirochetes were detected by periodic microscopy after three to 15 days incubation without passage. A single $B$. mayonii culture required blind-passage on day eight into fresh BSK-R at a dilution of $1 \%(\mathrm{v} / \mathrm{v})$ for detection of spirochetes; this sample was not received until 38 days post collection with considerable hemolysis evident. In all cases, recovered spirochetes were subsequently propagated to densities $\geq 5 \times 10^{6}$ spirochetes $/ \mathrm{mL}$. Starting inocula were estimated at $<10^{3}$ to $10^{7}$ spirochetes based on microscopic quantitation of the original blood samples. A microscopic limit of detection of $8.3 \times 10^{3}$ spirochetes $/ \mathrm{mL}$ blood (one spirochete in 600 fields of blood diluted 1:10) precluded determination of spirochete numbers lower than $10^{3}$. The average time for microscopic detection of spirochetes in B. hermsii, B. turicatae and B. mayonii recovered cultures was six, seven, and nine days, respectively. The single $B$. miyamotoi isolate required 15 days of growth for detection. The quality of the blood specimen (hemolysis, contamination, length of time from collection to culture), the level of spirochetemia and the infecting Borrelia species were associated with the time to microscopic detection of spirochetes in culture. Lower inocula and low-quality specimens correlated with longer recovery times. One $B$. hermsii isolate was successfully recovered from blood collected two days after azithromycin treatment, while the B. burgdorferi isolate was recovered from a heavily contaminated blood specimen. All recovered isolates were verified to species level by PCR, eight housekeeping gene multi-locus sequence typing or $16 \mathrm{~S}$ sequencing.

Direct recovery of $B$. burgdorferi and B. miyamotoi was also achieved when single field-collected I. scapularis adult ticks $(\mathrm{n}=55)$ were homogenized and inoculated into BSK-R with antibiotics. Twenty-six isolates of $B$. burgdorferi were readily obtained within seven days of growth and confirmed by PCR (ospA positive, $g l p Q$ negative). Markedly, both B. burgdorferi and B. miyamotoi were simultaneously recovered in BSK-R within seven 


\begin{tabular}{|c|c|c|c|c|c|c|c|c|}
\hline Borrelia group & Borrelia species & $\begin{array}{l}\text { Length of time } \\
\text { (days) between } \\
\text { blood collection } \\
\text { and culture }\end{array}$ & $\begin{array}{l}\text { Concentration of } \\
\text { spirochetes per } \\
\text { mL blood based } \\
\text { on microscopy }\end{array}$ & $\begin{array}{l}\text { Motile spirochetes } \\
\text { (\%) in blood }\end{array}$ & $\begin{array}{l}\text { Blood volume } \\
\text { inoculated }(\mu \mathrm{L})\end{array}$ & $\begin{array}{l}\text { No. of spirochetes } \\
\text { inoculated }\end{array}$ & $\begin{array}{l}\text { Time to detection } \\
\text { of spirochetes } \\
\text { in BSK-R: } \\
\text { concentration } \\
\text { (spirochetes/mL) }\end{array}$ & References \\
\hline \multirow{16}{*}{ Relapsing fever } & B. miyamotoi & 8 & $<8.2 \times 10^{3}$ & NA & 500 & $<4.1 \times 10^{3}$ & Day $15: 2.0 \times 10^{4}$ & Unpublished \\
\hline & B. hermsii & 4 & $2.5 \times 10^{5}$ & $100 \%$ & 50 & $1.3 \times 10^{4}$ & Day 4: $8.2 \times 10^{3}$ & 37 \\
\hline & B. hermsii & 4 & $2.5 \times 10^{4}$ & $100 \%$ & 50 & $1.3 \times 10^{3}$ & Day 8: $1.5 \times 10^{5}$ & 37 \\
\hline & B. hermsii & 4 & $2.5 \times 10^{4}$ & $100 \%$ & 50 & $1.3 \times 10^{3}$ & Day 8: $3.5 \times 10^{5}$ & 37 \\
\hline & B. hermsii & 4 & $2.5 \times 10^{4}$ & $100 \%$ & 50 & $1.3 \times 10^{3}$ & Day 4: $5.0 \times 10^{4}$ & 37 \\
\hline & B. hermsii & 6 & $2.9 \times 10^{6}$ & $100 \%$ & 50 & $1.4 \times 10^{5}$ & Day 3: $6.0 \times 10^{4}$ & Unpublished \\
\hline & B. hermsii & 5 & $<2.5 \times 10^{4}$ & NA & 100 & $<2.5 \times 10^{3}$ & Day $7: 6.7 \times 10^{3}$ & Unpublished \\
\hline & B. hermsii & 7 & $8.8 \times 10^{7}$ & $1 \%$ & 100 & $8.8 \times 10^{6}$ & Day 5: $7.1 \times 10^{6}$ & Unpublished \\
\hline & B. hermsii & 5 & $2.0 \times 10^{5}$ & $100 \%$ & 500 & $1.0 \times 10^{5}$ & Day 7: $1.0 \times 10^{4}$ & Unpublished \\
\hline & B. hermsii ${ }^{\mathrm{a}}$ & 9 & $1.5 \times 10^{5}$ & $17 \%$ & 500 & $7.5 \times 10^{4}$ & Day 6: $1.5 \times 10^{4}$ & Unpublished \\
\hline & B. hermsii & 3 & $3.6 \times 10^{6}$ & $83 \%$ & 500 & $1.8 \times 10^{6}$ & Day 5: $1.7 \times 10^{7}$ & Unpublished \\
\hline & B. hermsii & 22 & $1.1 \times 10^{7}$ & $0 \%$ & 500 & $5.5 \times 10^{6}$ & Day 8: $1.6 \times 10^{8}$ & Unpublished \\
\hline & B. hermsii & 17 & $3.0 \times 10^{7}$ & $0 \%$ & 500 & $1.5 \times 10^{7}$ & Day 7: $9.3 \times 10^{6}$ & Unpublished \\
\hline & B. turicatae & 6 & $<4.9 \times 10^{4}$ & NA & 100 & $<4.9 \times 10^{3}$ & Day $7: 3.5 \times 10^{7}$ & 38,39 \\
\hline & B. turicatae & 9 & $<8.2 \times 10^{3}$ & NA & 500 & $<4.1 \times 10^{3}$ & Day 7: $5.0 \times 10^{4}$ & 34 \\
\hline & B. turicatae & 7 & $<8.2 \times 10^{3}$ & NA & 500 & $<4.1 \times 10^{3}$ & Day 7: $5.6 \times 10^{7}$ & 34 \\
\hline \multirow{5}{*}{ Lyme } & B. mayonii & 5 & $1.5 \times 10^{5}$ & $100 \%$ & 50 & $<7.5 \times 10^{3}$ & Day 6: $1.5 \times 10^{6}$ & $11,35,40$ \\
\hline & B. mayonii & 39 & $<2.5 \times 10^{4}$ & NA & 50 & $<1.3 \times 10^{3}$ & Day 16: $9 \times 10^{5 b}$ & 11,40 \\
\hline & B. mayonii & 8 & $<8.2 \times 10^{3}$ & NA & 500 & $<4.1 \times 10^{3}$ & Day $7: 1 \times 10^{5}$ & Unpublished \\
\hline & B. mayonii & Unknown & $8.0 \times 10^{3}$ & $50 \%$ & 500 & $<4.0 \times 10^{3}$ & Day $7: 4 \times 10^{6}$ & Unpublished \\
\hline & B. burgdorferi & 17 & $<8.2 \times 10^{3}$ & NA & 500 & $<4.1 \times 10^{3}$ & Day $13=1.7 \times 10^{5}$ & Unpublished \\
\hline
\end{tabular}

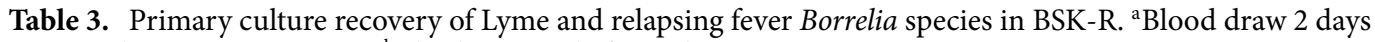
post azythromycin treatment. ${ }^{b}$ Blind passaged after 8 days.

days of inoculating two co-infected ticks. Concurrent culture recovery of both B. burgdorferi and B. miyamotoi was confirmed by PCR (ospA and $g l p Q$ positive) and sequencing.

\section{Discussion}

BSK-R, a diluted BSK-II derivative supplemented with Lebovitz's L-15, mouse and fetal calf serum, was developed and successfully used for the direct in vitro isolation of 15 freezer-retrievable isolates of $B$. miyamotoi originating from animal and tick sources in the eastern or upper midwestern U.S. This media also broadly supported growth of 15 other Borrelia species encompassing the RF group as well as the LB group, all of which grew from frozen stocks to unpassaged cell densities of $>10^{7}$ spirochetes $/ \mathrm{mL}$. Notably, primary cultures (21 isolates) of $B$. miyamotoi, B. hermsii, B. turicatae, B. burgdorferi and B. mayonii were successfully recovered from the blood of infected patients using BSK-R. These include the first isolations from human cases in the U.S. for the two emerging pathogens, $B$. miyamoto $i$ (this report) and $B$. mayonii ${ }^{11}$.

Unexpectedly, we discovered North American B. miyamotoi only grew in BSK-IIB-MS when all components were diluted with water. This finding yielded the single most important media modification for successful growth of B. miyamotoi. The primary component responsible for growth inhibition was CMRL 1066. Decreasing its final concentration by $50 \%$ to $4.04 \mathrm{~g} / \mathrm{L}$, with all other components held constant, enabled initial growth of $B$. miyamotoi, although it was not sufficient for sustained propagation. The concentration of motile bacteria arrested at day four, suggesting at least one other component of BSK-IIB-MS also negatively impacts B. miyamotoi growth. CMRL 1066 was originally incorporated into Stoenner's enrichment of Kelly's medium [final concentration estimated to be $4.87 \mathrm{mg} / \mathrm{mL}$ ( $5 \%$ of a 10X solution)] to improve antigen expression and growth of $B$. hermsii ${ }^{17}$. The concentration of CMRL 1066 in BSK-II, which was optimized for growth of B. burgdorferi, is $\sim 7.1 \mathrm{mg} /$ $\mathrm{mL}^{18}$. The concentration of CMRL 1066 in BSK-H is $\sim 10 \mathrm{mg} / \mathrm{mL}$. We postulate the higher concentration of CMRL 1066 and other components is why B. miyamotoi from ticks and patients in the U.S. was not cultivable in this medium ${ }^{13,14}$. Although Lebovitz's L-15 augmented growth of B. miyamotoi, it was not able to substitute for CMRL 1066 (data not shown). Lebovitz's L-15, like CMRL 1066, is comprised of amino acids and vitamins, but without other factors present in CMRL 1066. It is buffered with salts, free base amino acids and galactose to help maintain physiological $\mathrm{pH}$ control in $\mathrm{CO}_{2}$ free systems ${ }^{19}$.

The sensitivity of Borrelia species to serum complement varies by animal source and has been linked to reservoir host competency in nature ${ }^{20}$. Initial incorporation of mouse serum into media formulations was based on evidence suggesting $B$. miyamoto $i$ is resistant to mouse serum complement. Borrelia miyamotoi was initially detected in mice in nature ${ }^{5}$. Additionally, mouse serum (CD1 and BALB/c) was not bactericidal for B. miyamotoi when tested in an in vitro assay, whereas rabbit serum was (data not shown). The negative effects of rabbit sera on B. miyamotoi could be decreased, but not eliminated, when serum was inactivated at $0.5 \mathrm{~h}$ at $56^{\circ} \mathrm{C}$. The 
observed sensitivity to rabbit serum complement is consistent with a prior study where $50 \%$ human serum, but not rabbit serum, was suitable for propagation of B. miyamoto $i^{21}$. Further inactivation of rabbit serum for $45 \mathrm{~min}$ and incorporation into BSK-R as the sole source of serum (13\%) was found to support growth of B. miyamotoi, albeit with lower spirochete motility and slower growth as compared to mouse serum. Nonetheless, this finding indicates rabbit serum, a less expensive alternative to mouse serum, can substitute when using BSK-R for propagation of Borrelia stock cultures. Continued work is needed to further define serum requirements for the direct in vitro recovery of North American B. miyamotoi.

Primary culture recovery of Borrelia species in BSK-R was successfully achieved from bloods, of infected patients, collected in EDTA and with spirochete concentrations estimated at $<10^{3}$ and of low quality (collected 39 days prior, no motile spirochetes, heavily contaminated, and post-antibiotic treatment). Initially, blood was seeded into BSK-R at dilutions no higher than $1 \%(\mathrm{v} / \mathrm{v})$, with no removal of blood components. Subsequently, this protocol was modified to include removal of EDTA and components released from hemolyzed blood cells, given their inhibitory effect on growth of B. miyamotoi and/or B. burgdorferi $i^{22-24}$. With this modification, larger blood volumes were successfully used for recovery of cultures.

The time to detection of B. miyamotoi in primary cultures was slowed and the unpassaged spirochete density lower when blood specimens versus tick homogenates were used as the starting inoculum. The two isolates recovered from animal and human blood both required $\sim 14$ days of growth in BSK-R for their detection, whereas the recovery time from tick homogenates was as low as seven days, even when B. burgdorferi was concurrently isolated. This suggests something about the inocula themselves, such as a higher spirochete number in ticks, an inhibitory component in blood or a growth component in ticks, might be responsible for this difference. PCR quantitation has been used to estimate the number of $B$. miyamotoi genome equivalents in blood from infected U.S. patients at $10^{4}-10^{5} / \mathrm{mL}^{25}$; whether the number of spirochetes in I. scapularis ticks is higher requires further investigation. Of note, primary culture recovery of $B$. miyamotoi from the plasma of patients in Russia also required incubation in MKP-F for 12-20 days ${ }^{22}$. The slowed time for primary recovery of $B$. miyamotoi is consistent with its longer doubling time as compared to other borreliae. A doubling time of $\sim 18 \mathrm{~h}$ was determined for U.S. B. miyamotoi in BSK-R and in MKP supplemented with $50 \%$ human serum ${ }^{21}$, whereas the doubling time for B. mayonii in BSK-R is $\sim 9 \mathrm{~h}$. Given primary isolation of $B$. miyamotoi from blood requires $\sim 14$ days, it's likely media components critical for growth deteriorate with age and why growth could be improved upon detection of spirochetes and transfer into fresh media.

An important consideration for Borrelia culture is whether the recovered isolate retains pathogenicity and infectivity. As shown previously for B. burgdorferi, differences in medium composition can significantly affect downstream experiments, due to the loss of plasmids ${ }^{26}$. Towards this end, B. miyamotoi and B. mayonii strains isolated in primary culture, using BSK-R, were used to successfully establish infection in CD1 or SCID mice via subcutaneous infection ${ }^{27-33}$. Borrelia mayonii infected CD1 mice also supported infection of I. scapularis via feeding ${ }^{32}$. Prior publications referred to BSK-R as either modified BSK or modified BSK-II ${ }^{11,15,16,27-40}$.

Borrelia miyamotoi was not isolated from I. pacificus in BSK-R, although it was successfully propagated in BSK-R, once an isolate was recovered via co-culture of infected SCID mouse blood with an embryonic tick cell line, ISE6. The reason for this is not clear and requires further work. Challenges occurred with transmission and feeding of I. pacificus on both immunocompetent and SCID mice and may have been due to the condition of the ticks. Mold was present in the maintained ticks and few spirochetes were observed in tick midguts. As sequences of B. miyamotoi from I. pacificus and I. scapularis have been shown to differ, it is also possible strain differences might be associated with recovery in BSK- $\mathrm{R}^{41}$.

While this work was in progress, two tick-derived isolations of North American B. miyamotoi were reported. M1029 and LB-2001 were isolated from SCID mouse plasma in MKP diluted with 50\% human serum and in MKP-F (which is diluted with $10 \%$ fetal calf serum), respectively ${ }^{21,42}$. We postulate that growth in these two cases is due to a reduced concentration of CMRL 1066; 3.2 and $6.3 \mathrm{~g} / \mathrm{L}$ for MKP containing $50 \%$ human serum and MKP-F, respectively, as well as other components. In the case of MKP supplemented with $50 \%$ human serum, the volume of serum added would also have reduced the concentrations of all other MKP ingredients by half ${ }^{21}$. While the addition of $50 \%$ human serum likely had a positive effect on growth, our finding that $B$. miyamotoi grew in BSK-IIB-MS diluted 50\% with water, suggests the reduction of MKP components by half may be the primary reason for growth of North American B. miyamotoi in this media.

Given the lengthy turnaround times and specialized growth requirements of Borrelia species, use of culture as a standard diagnostic test is limited. Nonetheless, its value should not be understated. Isolation of Borrelia species is paramount to a better understanding of the natural biology and pathogenesis of newly identified human pathogens or those which represent distinct geographic and ecological niches. Additionally, the public health importance of Borrelia species dictates the use of culture as a diagnostic benchmark for a true understanding of the geographic regions these infections occur. The development of a media formulation that enables growth and direct isolation of both RF and LB Borrelia species, should help to improve our understanding of these important tick-transmitted pathogens. Given that batch/lot differences of BSK ingredients have previously been shown to influence spirochete recovery ${ }^{10}$ further research directed towards optimization and standardization of BSK-R as well as simplification is important.

\section{Materials and methods}

Specimen sources. Adult I. scapularis were collected in South Kingstown, Rhode Island and Danbury, Ridgefield, and Newtown, Connecticut. Adult I. pacificus were collected in Napa, Marin, Sonoma, and Santa Clara, California. Adult ticks were fed on New Zealand White rabbits (Harlan, Indianapolis, IN). Post-ovaposition females were tested by TaqMan PCR for B. burgdorferi and B. miyamotoi. Borrelia miyamotoi PCR positive egg clutches were incubated in desiccators at $21^{\circ} \mathrm{C}$ and $>97 \% \mathrm{RH}$ in Wheaton vials (Millville, NJ) containing 
plaster of Paris and activated charcoal and allowed to hatch to larvae. Larvae (5-100 per mouse) were allowed to feed to repletion on CD1 mice and molt to nymphs. Blood was collected in EDTA tubes from small mammals live trapped in Minnesota ${ }^{35}$. All work with laboratory mice was approved by the Centers for Disease Control (CDC) and Prevention Division of Vector-Borne Diseases Animal Care and Use Committee in accordance with the Animal Welfare Act. Human EDTA whole blood specimens were submitted for Borrelia diagnostic testing or were residual samples from research studies.

Mouse infection. Approximately $200 \mathrm{I}$. scapularis eggs, were surface sterilized by submerging in $\mathrm{H}_{2} \mathrm{O}_{2}$ for one minute, rinsed with sterile saline, submerged in $70 \%$ ethanol for $2 \mathrm{~min}$, rinsed again and ground in a $1.7 \mathrm{~mL}$ Eppendorf tube containing $200 \mu \mathrm{Ls}$ sterile saline using a plastic pestle. BALB/c mice were inoculated subcutaneously with $100 \mu \mathrm{Ls}$ of egg homogenate. To infect SCID mice, I. pacificus nymphal ticks (3 per mouse) were allowed to feed to repletion. Mice were euthanized and blood collected by cardiac puncture without the use of anticoagulant.

Tick cell co-culture. I. scapularis embryonic (ISE6) cells ${ }^{43}$ were cultivated in tissue culture flasks with plug seal caps at $34{ }^{\circ} \mathrm{C}$ with caps tight. Tick Cell Co-culture Media (TCCM) consisted of $90 \%$ L-15B300, prepared according to Munderloh ${ }^{44}$ and $10 \%$ BSK-IIB, a modification of the media used to culture Borrelia lonestari ${ }^{45}$. For seeding confluent cell cultures, $20-250 \mu \mathrm{L}$ of infected mouse blood was added to flasks. Media was replaced every 7-10 days, by decanting, followed by centrifugation at $3300(\mathrm{~g})$ for $8 \mathrm{~min}$. The supernatant was discarded, the resultant pellet resuspended in 5-6 mL fresh media and transferred back into the flask.

Culture in BSK formulations. For development of BSK-R, early passage (P2) non-frozen and frozen stocks $\left(-80^{\circ} \mathrm{C}\right)$ of $B$. miyamotoi strain RI13-2395 were used. Frozen stocks were prepared in cryovials by adding glycerol to a final concentration of $18 \%$ and placing into cryo $1{ }^{\circ} \mathrm{C}$ freezing containers (Thermo Fisher, Waltham, MA) at $-80^{\circ} \mathrm{C}$ for $24 \mathrm{~h}$. Frozen stocks were warmed at $-20^{\circ} \mathrm{C}$ for approximately $30 \mathrm{~min}$ followed by placing at $4{ }^{\circ} \mathrm{C}$ or in ice bucket until thawed $(\sim 15-30 \mathrm{~min})$. For side-by-side media comparisons, multiple stocks were thawed, combined into a single tube and mixed by inverting. For direct comparison of BSK-R and BSK-IIB media formulations, frozen $\left(-80^{\circ} \mathrm{C}\right)$ strains were thawed and mixed, and the same volume simultaneously inoculated into both media. Cultures were followed by microscopy until an unpassaged peak density for motile spirochetes was achieved.

Frozen aliquots of media were used for all experiments unless indicated. For preparation of BSK-IIB-MS formulations combined with $\mathrm{H}_{2} 0$, filtered MilliQ $\mathrm{H}_{2} \mathrm{O}$ was added at the indicated ratio to complete BSK-IIB-MS media. For preparation of BSK-IIB-MS with single ingredients reduced by half, the final concentration of all other ingredients remained unchanged; media was freshly prepared and not frozen.

For inoculation of BSK-R, $50 \mu \mathrm{L}$ of EDTA whole blood from field collected animals was added, followed by gentle mixing via pipetting. Red blood cells (RBCs) were allowed to settle for $48 \mathrm{~h}$ and the supernatant transferred to a new tube. EDTA was not removed. Ixodes ticks were surface sterilized by $3 \% \mathrm{H}_{2} \mathrm{O}_{2}(5 \mathrm{~min})$ and $70 \%$ ethanol (11 min) washes and air dried on bibulous paper. Nymphs minced with scalpels on glass slides and adults homogenized using Wheaton Tenbroeck tissue grinders (DWK Life Sciences Millville, NJ) were inoculated into cultures. 50-500 $\mu \mathrm{Ls}$ of EDTA whole blood from patients was used to seed cultures. If blood volumes larger than $100 \mu \mathrm{Ls}$ were inoculated, red blood cells (RBCs) were allowed to settle overnight. To remove EDTA and red blood cell components, the resulting supernatant was removed and centrifuged at $3300(\mathrm{~g})$ for $8 \mathrm{~min}$, with the pellet resuspended in fresh media.

All cultures were incubated in $5 \mathrm{~mL}$ or $14 \mathrm{~mL}$ snap cap round bottom polypropylene Falcon tubes or $5 \mathrm{~mL}$ Eppendorf centrifuge tubes at $34^{\circ} \mathrm{C}$ with tubes filled to $90 \%$ capacity and caps pressed on tight, creating a microaerophilic environment. BSK-R seeded with blood from infected animals or patients was refreshed after approximately two weeks of culture; supernatants were removed, and centrifuged at 3,300(g) for 8 min, with the pellet resuspended in fresh media. Tubes were examined periodically by dark field microscopy for spirochete growth.

Cultures. The Japanese strains of B. miyamotoi, HT31, HT24 and FR64b, were kindly provided by Dr. Fukunaga via Dr. Barbara Johnson. Strain LB2001 was provided by Dr. Joppe Hovius (The Academic Medical Center in the Department of Internal Medicine, Division of Infectious Diseases). Borrelia bissettii (DSM 17990), B. valaisiana (DSM 21467), B. spielmanii (DSM 16813), B. sinica (DSM 23262), B. yangtzensis (DSM 24625), and B. lanei (DSM 17992) were obtained from DSMZ. Borrelia hermsii (NE95-0544), B. mayonii (MN14-1420, MN141539), B. burgdorferi (B31), B. parkeri (MT90-0900), B. coriaceae (89-1425), B. turicatae (TX15-4645), and B. recurrentis (SU99-0699) were from the CDC reference collection.

Microscopy. Wet mounts for dark field microscopy were prepared by pipetting $5 \mu$ Ls of culture or a 1:10 dilution of whole blood onto a glass slide and covering with a $22 \mathrm{~mm} \times 22 \mathrm{~mm}$ coverslip. Wet mounts were visualized using an Axio Imager.A2 microscope (Ziess, Thornwood, NY) at a total magnification of 400X. The number of spirochetes per field was determined by counting motile spirochetes in at least 20 fields. The exception was for human blood specimens, where both motile and non-motile spirochetes were counted. The number of spirochetes per $\mathrm{mL}$ was determined as follows: average number of spirochetes per $400 \mathrm{X}$ field $\times\left(5 \times 10^{5}\right.$ spirochetes $/ \mathrm{mL}$ ) dilution factor. The conversion factor was determined as previously described ${ }^{11}$. Spirochete motility was assessed based on observation of rapid corkscrewing movement. 
DNA extraction, PCR and sequencing. Female ticks or egg clutches ( 50-400) were placed in a MagNA Lyser green bead tube (Roche, Indianapolis, IN) with tissue lysis buffer (Roche) and homogenized in a MagNA Lyser (Roche) at $6500 \mathrm{rpm}$ for $50 \mathrm{~s}$, once for eggs, three times for adults, and DNA extracted using a MagNA Pure 96 (Roche). DNA from mouse blood and cultures was extracted using the QIAamp DNA Mini kit (Qiagen, Valencia, CA).

Borrelia miyamotoi glpQ primers and probe were modified from Ullmann et al. ${ }^{46}$ : BmglpQ-F GACAATATT CCTGTTATAATGC, BmglpQ-R CACTGAGATTTAGTGATTTAAGTTC, and BmglpQ-P FAM-CCCAGAAAT TGACACAACCAC-BHQ1. The B. burgdorferi ospA primers were modified from Ivacic et al. ${ }^{47}$ : OspA-F AAT ATTTATTGGGAATAGGTCTAA, OspA-R CACCAGGCAAATCTACTGA and TTAATAGCATGTAAGCAA AATGTTAGCA-BHQ1. Each $20 \mu \mathrm{L}$ PCR reaction contained $5 \mathrm{mM} \mathrm{MgCl}_{2}, 500 \mathrm{nM}$ each primer, $100 \mathrm{nM}$ probe, $1 \times$ PerfeCta qPCR FastMix II Low ROX (Quanta Biosciences, Beverly, MA), $5 \mu$ L DNA extract. Cycling conditions on the 7500 FAST Dx (Applied Biosystems, Foster City, CA) were $95^{\circ} \mathrm{C} 3 \mathrm{~min}$, and 50 cycles of $95^{\circ} \mathrm{C}$ for $10 \mathrm{~s}$ and $57^{\circ} \mathrm{C}$ for $30 \mathrm{~s}$. PCR assays for $B$. turicatae and $B$. hermsii were as described ${ }^{48}$. For sequencing, primers were glpQ-F GGAGCTGACTACCTAGAAC, glpQ-R GGGTATCCAAGGTCCAATTCC, 16 s-F CCTGGCTTA GAACTAACG, and 16 s-R TTCGCCTCTGGTATTCTTCC. Reactions were as previously described ${ }^{34}$. Consensus sequences were assembled with Clone Manager 9.3 (Sci-Ed, Denver, CO) and aligned to Borrelia sequences in GenBank. One to eight housekeeping genes were amplified, sequenced, and analyzed for identification of $B$. mayonii ${ }^{25}$.

Media formulations. To prepare $600 \mathrm{~mL}$ of an in-house formulation for B. hermsii growth, (here termed BSK-IIB), 500 mL Milli-Q water and 25.0 g universal grade Bovine Serum Albumin (BSA) (Millipore Sigma, St. Louis, MO) was added to a $1 \mathrm{~L}$ flask and stirred slowly until fully dissolved. The following reagents were next added, one at a time, ensuring each reagent was fully dissolved before addition of others; $4.85 \mathrm{~g}$ CMRL 1066 10X w/o L-glutamine, powder, (US Biological, Salem, MA), 2.5 g Gibco Bacto neopeptone (Fisher Scientific, Pittsburgh, PA), 3.0 g HEPES sodium salt (Fisher Scientific), 0.35 g sodium citrate (Millipore Sigma), $3.5 \mathrm{~g}$ D-(+)-Glucose (Millipore Sigma), 0.4 g sodium pyruvate, sodium salt (Millipore Sigma), 0.2 g N-acetyl-D-glucosamine (MP Biomedicals, Irvine, CA), $1.1 \mathrm{~g}$ sodium bicarbonate, anhydrous (Millipore Sigma), $1.0 \mathrm{~g}$ Gibco Bacto TC yeastolate (Fisher Scientific), and $0.14 \mathrm{~g}$ tissue culture grade L-cysteine $\mathrm{HCl}$ monohydrate (Fisher Scientific). Once all reagents were fully dissolved, $72 \mathrm{~mL}$ of heat inactivated $\left(56^{\circ} \mathrm{C}\right.$ for $\left.45 \mathrm{~min}\right)$ sterile, trace hemolyzed rabbit serum (Pel-Freez, Rogers, AR) was added followed by $0.04 \mathrm{~g}$ Invitrogen UltraPure dithiothreitol (DTT) (Fisher Scientific). Finally, the pH was adjusted to 7.5 and antibiotics were added followed by filter sterilization using a $0.22 \mu \mathrm{m}$ Millipore Express PLUS filtration system (Millipore Sigma). This same formulation with substitution of heat inactivated $\left(56^{\circ} \mathrm{C}\right.$ for $30 \mathrm{~min}$ ) $\mathrm{BALB} / \mathrm{c}$ mouse serum (Innovative Research, Novi, MI) in place of rabbit serum was termed BSK-IIB-MS.

To prepare $600 \mathrm{~mL}$ of BSK-R, $300 \mathrm{~mL}$ Milli-Q water and $15.0 \mathrm{~g}$ BSA (universal grade) was added to a $1 \mathrm{~L}$ flask and stirred slowly until fully dissolved. Simultaneously, $200 \mathrm{~mL}$ Milli-Q water and $3.0 \mathrm{~g}$ Gibco Leibovitz's L-15 medium, powder (Fisher Scientific) was added to a $500 \mathrm{~mL}$ flask and stirred slowly until fully dissolved. To the $1 \mathrm{~L}$ flask containing fully dissolved BSA, the following reagents were added one at a time ensuring each reagent was fully dissolved before addition of next one; $2.6 \mathrm{~g}$ CMRL 1066 10X w/o L-glutamine (powder), $1.5 \mathrm{~g}$ Gibco Bacto neopeptone, $1.3 \mathrm{~g}$ HEPES sodium salt, $0.21 \mathrm{~g}$ sodium citrate, $3.0 \mathrm{~g}$ D-( +)-Glucose, $0.24 \mathrm{~g}$ sodium pyruvate, sodium salt, $0.12 \mathrm{~g} \mathrm{~N}$-acetyl-D-glucosamine, $0.59 \mathrm{~g}$ sodium bicarbonate, $0.6 \mathrm{~g}$ Gibco Bacto TC yeastolate and $0.084 \mathrm{~g} \mathrm{~L}$-cysteine $\mathrm{HCl}$ monohydrate. After reagents were fully dissolved, $24 \mathrm{~mL}$ heat inactivated $\left(56^{\circ} \mathrm{C}\right.$ for $45 \mathrm{~min}$ ) trace hemolyzed, sterile rabbit serum, $42 \mathrm{~mL}$ heat inactivated $\left(56^{\circ} \mathrm{C}\right.$ for $\left.30 \mathrm{~min}\right) \mathrm{BALB} / \mathrm{c}$ mouse serum and $12 \mathrm{~mL}$ heat inactivated $\left(56^{\circ} \mathrm{C}\right.$ for $30 \mathrm{~min}$ ) Corning premium fetal bovine serum (FBS) (Fisher Scientific) were added to the same flask, followed by $0.024 \mathrm{~g}$ Invitrogen UltraPure DTT and the fully dissolved Leibovitz's L-15 medium. Finally, the $\mathrm{pH}$ was adjusted to 7.5, antibiotics were added and the media filter sterilized as above.

The final concentrations of antibiotics included $0.05 \mathrm{~g} / \mathrm{L}$ rifampicin (Fisher Scientific), $0.02 \mathrm{~g} / \mathrm{L}$ cycloheximide (Fisher Scientific), $0.2 \mathrm{~g} / \mathrm{L}$ phosphomycin (MP Biomedicals), and $0.0025 \mathrm{~g} / \mathrm{L}$ ( $6 \mathrm{~mL}$ of a $250 \mu \mathrm{g} / \mathrm{mL}$ solution) amphotericin B (Fisher Scientific).

Single use aliquots of complete media (including serum and antibiotics) were prepared in $5 \mathrm{~mL}$ or $14 \mathrm{~mL}$ falcon tubes and stored at $-20^{\circ} \mathrm{C}$ in the dark for up to one year.

Ethics statement. The secondary use of residual samples described herein was performed in accordance with the relevant guidelines and regulations under a protocol approved by the CDC Institutional Review Board with an approved waiver of informed consent. The views and opinions expressed herein are those of the authors alone and do not represent the official position of the Centers for Disease Control and Prevention.

Received: 3 June 2020; Accepted: 16 December 2020

Published online: 21 January 2021

\section{References}

1. Aguero-Rosenfeld, M. E., Wang, G., Schwartz, I. \& Wormser, G. P. Diagnosis of Lyme borreliosis. Clin. Microbiol. Rev. 18(3), 484-509. https://doi.org/10.1128/CMR.18.3.484-509.2005 (2005).

2. Cutler, S. J. et al. Diagnosing borreliosis. Vector Borne Zoonotic Dis. 17(1), 2-11. https://doi.org/10.1089/vbz.2016.1962 (2017)

3. Paules, C. I., Marston, H. D., Bloom, M. E. \& Fauci, A. S. Tickborne diseases-confronting a growing threat. N Engl J Med. 379, 701-703. https://doi.org/10.1056/NEJMp1807870 (2018).

4. Rosenberg, R. et al. Vital signs: trends in reported vectorborne disease cases-United States and territories, 2004-2016. $M M W R$ Morb. Mortal. Wkly. Rep. 67, 496-501. https://doi.org/10.15585/mmwr.mm6717e1 (2018). 
5. Fukunaga, M. et al. Genetic and phenotypic analysis of Borrelia miyamotoi sp nov., isolated from the ixodid tick Ixodes persulcatus, the vector for Lyme disease in Japan. Int. J. Syst. Bacteriol. 45(4), 804-810. https://doi.org/10.1099/00207713-45-4-804 (1995).

6. Barbour, A. G. Cultivation of Borrelia: a historical overview. Zentralbl Bakteriol Mikrobiol Hyg. Ser. A. 263(1-2), 11-14. https:// doi.org/10.1016/S0176-6724(86)80095-5 (1986).

7. Kelly, R. Cultivation of Borrelia hermsi. Science 173(3995), 443-444. https://doi.org/10.1126/science.173.3995.443 (1971).

8. Barbour, A. G., Burgdorfer, W., Hayes, S. F., Peter, O. \& Aeschlimann, A. Isolation of a cultivable spirochete from Ixodes ricinus ticks of Switzerland. Curr. Microbiol. 8(2), 123-126. https://doi.org/10.1007/BF01566969 (1983).

9. Preac-Mursic, V., Wilske, B. \& Schierz, G. European Borrelia burgdorferi isolated from humans and ticks culture conditions and antibiotic susceptibility. Zentralbl Bakteriol Mikrobiol Hyg Ser. A. 263(1-2), 112-118. https://doi.org/10.1016/S0176-6724(86) 80110-9 (1986).

10. Pollack, R. J., Telford, S. R. 3rd. \& Spielman, A. Standardization of medium for culturing Lyme disease spirochetes. J. Clin. Microbiol. 31(5), 1251-1255 (1993).

11. Pritt, B. S. et al. Identification of a novel pathogenic Borrelia species causing Lyme borreliosis with unusually high spirochaetaemia: a descriptive study. Lancet Infect. Dis. 16(5), 556-564. https://doi.org/10.1016/S1473-3099(15)00464-8 (2016).

12. Platonov, A. E. et al. Humans infected with relapsing fever spirochete Borrelia miyamotoi, Russia. Emerg. Infect. Dis. 17(10), 1816-1823. https://doi.org/10.3201/eid1710.101474 (2011).

13. Gugliotta, J. L., Goethert, H. K., Berardi, V. P. \& Telford, S. R. 3rd. Meningoencephalitis from Borrelia miyamotoi in an immunocompromised patient. N. Engl. J. Med. 368(3), 240-245. https://doi.org/10.1056/NEJMoa1209039 (2013).

14. Scoles, G. A., Papero, M., Beati, L. \& Fish, D. A relapsing fever group spirochete transmitted by Ixodes scapularis ticks. Vector Borne Zoonotic Dis. 1(1), 21-34. https://doi.org/10.1089/153036601750137624 (2001).

15. Kingry, L. C. et al. Toward a complete North American Borrelia miyamotoi genome. Genome Announc. 5(5), e01557-e1616. https:// doi.org/10.1128/genomeA.01557-16 (2017).

16. Kingry, L. C. et al. Chromosome and large linear plasmid sequences of a Borrelia miyamotoi strain isolated from Ixodes pacificus ticks from California. Genome Announc. 5(37), e00960-e1017. https://doi.org/10.1128/genomeA.00960-17 (2017).

17. Stoenner, H. G., Dodd, T. \& Larsen, C. Antigenic variation of Borrelia hermsii. J. Exp. Med. 156(5), 1297-1311. https://doi.org/10. 1084/jem.156.5.1297 (1982).

18. Barbour, A. G. Isolation and cultivation of Lyme disease spirochetes. Yale J. Biol. Med. 57(4), 521-525 (1984).

19. Leibovitz, A. The growth and maintenance of tissue-cell cultures in free gas exchange with the atmosphere. Am. J. Epidemiol. 78(2), 173-180. https://doi.org/10.1093/oxfordjournals.aje.a120336 (1963).

20. Kurtenbach, K., Sewell, H. S., Ogden, N. H., Randolph, S. E. \& Nuttall, P. A. Serum complement sensitivity as a key factor in Lyme disease ecology. Infect. Immun. 66(3), 1248-1251. https://doi.org/10.1128/iai.66.3.1248-1251.1998 (1998).

21. Margos, G. et al. Long-term in vitro cultivation of Borrelia miyamotoi. Ticks Tick Borne Dis. 6(2), 181-184. https://doi.org/10. 1016/j.ttbdis.2014.12.001 (2015).

22. Koetsveld, J. et al. Development and optimization of an in vitro cultivation protocol allows for isolation of Borrelia miyamotoi from patients with hard tick-borne relapsing fever. Clin. Microbiol. Infect. 23(7), 480-484. https://doi.org/10.1016/j.cmi.2017.01. 009 (2017)

23. Marques, A. R. et al. Citrate anticoagulant improves the sensitivity of Borreliella (Borrelia) burgdorferi plasma culture. J. Clin. Microbiol. 55(11), 3297-3299. https://doi.org/10.1128/JCM.01046-17 (2017).

24. Benach, J. L. et al. Spirochetes isolated from the blood of two patients with Lyme disease. N. Engl. J. Med. 308, 740-742. https:// doi.org/10.1056/NEJM198303313081302 (1983).

25. Kingry, L. C. et al. Surveillance for and discovery of Borrelia species in US patients suspected of tickborne illness. Clin. Infect. Dis. 66, 1864-1871. https://doi.org/10.1093/cid/cix1107 (2018).

26. Wang, G. et al. Variations in Barbour-Stoenner-Kelly culture medium modulate infectivity and pathogenicity of Borrelia burgdorferi clinical isolates. Infect. Immun. 72(11), 6702-6706. https://doi.org/10.1128/IAI.72.11.6702-6706.2004 (2004).

27. Dolan, M. C. et al. Vector competence of the blacklegged tick, Ixodes scapularis, for the recently recognized Lyme borreliosis spirochete Candidatus Borrelia mayonii. Ticks Tick Borne Dis. 7(5), 665-669. https://doi.org/10.1016/j.ttbdis.2016.02.012 (2016).

28. Lynn, G. E. et al. An immunocompromised mouse model to infect Ixodes scapularis ticks with the relapsing fever spirochete, Borrelia miyamotoi. Tick Borne Dis. 10(2), 352-359. https://doi.org/10.1016/j.ttbdis.2018.11.017 (2019).

29. Breuner, N. E., Hojgaard, A., Replogle, A. J., Boegler, K. A. \& Eisen, L. Transmission of the relapsing fever spirochete, Borrelia miyamotoi, by single transovarially-infected larval Ixodes scapularis ticks. Ticks Tick Borne Dis. 9(6), 1464-1467. https://doi.org/ 10.1016/j.ttbdis.2018.07.006 (2018).

30. Dolan, M. C. et al. Transmission of the Lyme disease spirochete Borrelia mayonii in relation to duration of attachment by nymphal Ixodes scapularis (Acari: Ixodidae). J. Med. Entomol. 54(5), 1360-1364. https://doi.org/10.1093/jme/tjx089 (2017).

31. Breuner, N. E. et al. Transmission of Borrelia miyamotoi sensu lato relapsing fever group spirochetes in relation to duration of attachment by Ixodes scapularis nymphs. Ticks Tick Borne Dis. 8(5), 677-681. https://doi.org/10.1016/j.ttbdis.2017.03.008 (2017).

32. Dolan, M. C. et al. Duration of Borrelia mayonii infectivity in an experimental mouse model for feeding Ixodes scapularis larvae. Ticks Tick Borne Dis. 8(1), 196-200. https://doi.org/10.1016/j.ttbdis.2016.11.002 (2017).

33. Eisen, L. et al. Comparison of vector efficiency of Ixodes scapularis (Acari: Ixodidae) from the northeast and upper midwest of the United States for the Lyme disease spirochete Borrelia mayonii. J. Med. Entomol. 54(1), 239-242. https://doi.org/10.1093/jme/ tjw160 (2017).

34. Campbell, S. B. et al. Evaluating the risk of tick-borne relapsing fever among occupational cavers-Austin, TX, 2017. Zoonoses Public Health. 66(6), 579-586. https://doi.org/10.1111/zph.12588 (2019).

35. Johnson, T. L. et al. Isolation of the Lyme disease spirochete Borrelia mayonii from naturally infected rodents in Minnesota. J. Med. Entomol. 54(4), 1088-1092. https://doi.org/10.1093/jme/tjx062 (2017).

36. Kingry, L. C. et al. Whole genome sequence and comparative genomics of the novel Lyme Borreliosis causing pathogen, Borrelia mayonii. PLoS ONE 11(12), e0168994. https://doi.org/10.1371/journal.pone.0168994 (2016).

37. Jones, J. M. et al. Tick-borne relapsing fever outbreak among a high school football team at an outdoor education camping trip, Arizona, 2014. Am. J. Trop. Med. Hyg. 95(3), 546-550. https://doi.org/10.4269/ajtmh.16-0054 (2016).

38. Kingry, L. C. et al. Chromosome and linear plasmid sequences of a 2015 human isolate of the tick-borne relapsing fever spirochete, Borrelia turicatae. Genome Announc. 4(4), e00655-e716. https://doi.org/10.1128/genomeA.00655-16 (2016).

39. Christensen, A. M. et al. Diagnosis and management of Borrelia turicatae infection in febrile soldier, Texas, USA. Emerg. Infect. Dis. 23(5), 883-884. https://doi.org/10.3201/eid2305.162069 (2017).

40. Pritt, B. S. et al. Borrelia mayonii sp. nov., a member of the Borrelia burgdorferi sensu lato complex, detected in patients and ticks in the upper midwestern United States. Int. J. Syst. Evol. Microbiol. 66(11), 4878-4880. https://doi.org/10.1099/ijsem.0.001445 (2016).

41. Salkeld, D. J., Nieto, N. C., Bonilla, D. L., Yoshimizu, M. H. \& Padgett, K. A. Borrelia miyamotoi infections in small mammals, California, USA. Emerg. Infect. Dis. 24(12), 2356-2359. https://doi.org/10.3201/eid2412.171632 (2018).

42. Wagemakers, A., Oei, A., Fikrig, M. M., Miellet, W. R. \& Hovius, J. W. The relapsing fever spirochete Borrelia miyamotoi is cultivable in a modified Kelly-Pettenkofer medium, and is resistant to human complement. Parasit. Vectors 7, 418. https://doi.org/10.1186/ 1756-3305-7-418 (2014). 
43. Munderloh, U. G., Liu, Y., Wang, M., Chen, C. \& Kurtti, T. J. Establishment, maintenance and description of cell lines from the tick Ixodes scapularis. J. Parasitol. 80(4), 533-543. https://doi.org/10.2307/3283188 (1994).

44. Munderloh, U. G. et al. Invasion and intracellular development of the human granulocytic ehrlichiosis agent in tick cell culture. J. Clin. Microbiol. 37(8), 2518-2524 (1999).

45. Varela, A. S. et al. First culture isolation of Borrelia lonestari, putative agent of southern tick-associated rash illness. J. Clin. Microbiol. 42(3), 1163-1169. https://doi.org/10.1128/JCM.42.3.1163-1169.2004 (2004).

46. Ullmann, A. J., Gabitzsch, E. S., Schulze, T. T., Zeidner, N. S. \& Piesman, J. Three multiplex assays for detection of Borrelia burgdorferi sensu lato and Borrelia miyamotoi sensu lato in field-collected Ixodes nymphs in North America. J. Med. Entomol. 42(6), 1057-1062. https://doi.org/10.1093/jmedent/42.6.1057 (2005).

47. Ivacic, L., Reed, K. D., Mitchell, P. D. \& Ghebranious, N. A LightCycler TaqMan assay for detection of Borrelia burgdorferi sensu lato in clinical samples. Diagn. Microbiol. Infect. Dis. 57(2), 137-143. https://doi.org/10.1016/j.diagmicrobio.2006.08.005 (2007).

48. Bissett, J. D. et al. Detection of tickborne relapsing fever spirochete, Austin, Texas, USA. Emerg. Infect. Dis. 24(11), $2003-2009$. https://doi.org/10.3201/eid2411.172033 (2018).

\section{Acknowledgements}

We thank public health and reference laboratories that submitted blood samples for diagnostic testing and Mark Pilgard for providing ISE6 tick cells.

\section{Author contributions}

A.J.R. performed all of the culture and microscopy work; C.S. performed PCR and sequencing; J.Y. and M.D. performed mouse work; M.D. performed tick work; N.C. and K.A.P. collected ticks; L.K. performed genome sequencing, A.R., M.S. and J.M.P. performed data analysis and wrote the manuscript. All authors read and edited the manuscript.

\section{Competing interests}

The authors declare no competing interests.

\section{Additional information}

Correspondence and requests for materials should be addressed to J.M.P.

Reprints and permissions information is available at www.nature.com/reprints.

Publisher's note Springer Nature remains neutral with regard to jurisdictional claims in published maps and institutional affiliations.

(c) (i) Open Access This article is licensed under a Creative Commons Attribution 4.0 International License, which permits use, sharing, adaptation, distribution and reproduction in any medium or format, as long as you give appropriate credit to the original author(s) and the source, provide a link to the Creative Commons licence, and indicate if changes were made. The images or other third party material in this article are included in the article's Creative Commons licence, unless indicated otherwise in a credit line to the material. If material is not included in the article's Creative Commons licence and your intended use is not permitted by statutory regulation or exceeds the permitted use, you will need to obtain permission directly from the copyright holder. To view a copy of this licence, visit http://creativecommons.org/licenses/by/4.0/.

This is a U.S. Government work and not under copyright protection in the US; foreign copyright protection may apply 2021 